\title{
Role of Vaccines on Human Health-A Review
}

\author{
Pradeep Kumar $^{1}$, Preeti Sharma ${ }^{2 *}$ \\ ${ }^{1}$ Professor, Department of Biochemistry, Santosh Medical College and Hospital, Ghaziabad, India \\ ${ }^{2}$ Associate Professor, Department of Biochemistry, Santosh Medical College and Hospital, Ghaziabad, India
}

*Address for Correspondence: Dr. Preeti Sharma, Associate Professor, Department of Biochemistry, Santosh Medical College and Hospital, Ghaziabad, India

E-mail: prcdri2003@yahoo.co.in

Received: 12 July 2018/ Revised: 15 Oct 2018/ Accepted: 10 Dec 2018

\begin{abstract}
In the early $15^{\text {th }}$ century, people were trying to induce immunity against smallpox by dried crust derived from smallpox lesions. Previous many such experiments were conducted which finally led to the birth of vaccines, and are available today in service of mankind for a number of diseases. The vaccines are designed to combat infection via generating immunity have portions of proteins called antigens. These antigens stimulate a number of cells in the immune system, including macrophages, $T$ cells, and B cells. An immune response begins when macrophages ingest these antigenic proteins, which enter the body and digest them into antigen fragments. From the existing literature knowledge about the vaccination, the current article will provide an overview of role of the vaccine on human health.
\end{abstract}

Key-words: B cells, Immune system, Influenza vaccine, Macrophages, Proliferating microorganisms, T cells

\section{INTRODUCTION}

The scientific study of the body's resistance to invasion by other organisms is done in immunology, and the medical science considers immunology the body's system of defence against disease-causing microorganisms and with disorders in that system's functioning. The concept of artificial induction of immunity came into existence when in the year 1796 Edward Jenner used cowpox injections to protect people from smallpox ${ }^{[1]}$, but its scientific basis could not be established until a century later, when it was recognized that infection is caused by proliferating microorganisms in the body and the body has certain chemical and cellular components that recognize and destroy foreign substances (antigens) within the body ${ }^{[2]}$. The clear understanding of the phenomenon of self defence against the infection laid the foundation of highly successful techniques of immunization that could trigger

How to cite this article

Kumar $\mathrm{P}$, Sharma P. Role of Vaccines on Human Health-A Review. SSR Inst. Int. J. Life. Sci., 2019; 5(1): 2122-2125.

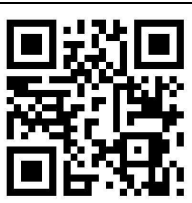

Access this article online www.ijlssr.com body's natural defences against infectious disease ${ }^{[3]}$. Basic techniques of vaccination ${ }^{[4]}$ have become increasingly selective and sophisticated in the manipulation of the body's immune system. Through selective use of drugs and other agents in efforts to achieve a desired therapeutic goal by modifying the immune system in a compromising manner, the field of modern immunology is flourishing each new day. Immunologic understanding is of great concern and crucial to reach the root cause of allergies and of course its treatment. Allergies are the hypersensitive reactions ${ }^{[5]}$ by the body's immune system against the presence of harmless antigens such as pollen grains, dust particles etc. Not only this, Immunology encompasses autoimmune diseases ${ }^{[6]}$, an extremely important area in the field of medicine, concerns body's immune system inability to discriminate between the self and non-self and immune system treats some constituent of its own tissues as if it were a foreign body ${ }^{[7]}$. The study of immune deficiencies ${ }^{[8]}$ has become an important area of intensive research since the appearance of AIDS (Acquired Immune Deficiency Syndrome) ${ }^{[9]}$. It is a disease that destroys the body's immune system and for which there is currently no cure, and life becomes miserable. Also knowledge of immunology has done 
wonders in saving the lives of millions of people through organ transplant. In fact many diseases can be cured by transplantation of healthy organs, tissues, or cells from one individual to another ${ }^{[10]}$; Immunosuppressive techniques use drugs to suppress the immune system's tendency of rejecting the antigenic bone grafts and organ transplants that have been medically introduced into the host tissue ${ }^{[11]}$.

Vaccination- Administration of antigenic materials to stimulate an individual's immune system to develop adaptive immunity to a pathogen to prevent or morbidity from infection is ameliorate vaccination ${ }^{[12]}$. A few examples are the influenza vaccine ${ }^{[13]}$, the HPV vaccine $^{[14]}$, and the chicken pox vaccine ${ }^{[15]}$ etc. Smallpox was the first disease for which a vaccine was produced and it was discovered in 1796 by the British physician Edward Jenner. Vaccination is the most effective method of preventing infectious diseases ${ }^{[7]}$. Louis Pasteur extended and contributed to vaccination concept through his work in microbiology ${ }^{[1]}$. The term vaccination was derived from the word cowpox; the disease which is caused by a virus specifically affecting cows (Latin: vacca-cow) ${ }^{[7]}$. A very contagious and deadly disease, the small pox is causing the deaths of $20-60 \%$ of infected adults and over $80 \%$ of infected children all over the world ${ }^{[16]}$. Smallpox was finally eradicated in 1979, while it has already killed an estimated $300-500$ million people in the $20^{\text {th }}$ century ${ }^{[17]}$. Effectiveness of vaccination has been widely studied and verified and widespread immunity due to vaccination is largely responsible for the worldwide eradication of smallpox and the restriction of diseases such as polio, measles, and tetanus from the society. Moreover licensed vaccines are currently available to prevent or contribute to the prevention and control of twenty-five preventable infections. The active agent present in the vaccine may be intact but inactivated ${ }^{[18]}$ (non-infective) or attenuated (with reduced infectivity) forms of the causative pathogens ${ }^{[18]}$ or purified components of the pathogen that have been found to be highly immunogenic [18] for example outer coat proteins of a virus, also some toxoids are produced for immunization against toxin-based diseases, such as the modification of tetano-spasmin toxin ${ }^{[19]}$ of tetanus to remove its toxic effect but retain its immunogenic effect. The word immunization is different from vaccination and distinguishes it from vaccination where inoculation of weakened live pathogens or dead carcasses of pathogens having significant antigenicity are intentionally introduced in the body. Vaccination efforts have been met with some controversy on scientific, ethical, political, medical safety, and religious grounds, while in rare cases of injury caused by vaccinations, a person may receive compensation for the coming under the 'injuries under the National Vaccine Injury Compensation Program, ${ }^{[20]}$. Widespread success and compulsion led to its acceptance globally and has greatly reduced the incidence of many diseases in numerous geographic regions.

Types of vaccine- There are four main types of vaccine currently in clinical use:

Inactivated vaccine- An inactivated vaccine consists of dead carcasses of virus or bacteria. These pathogens are grown in culture and then killed using a method such as heat or formaldehyde, which are unable replicate but the virus capsid proteins or bacterial wall are intact enough to be recognized and remembered by the immune system and evoke a response ${ }^{[18]}$. Sometimes improper inactivation of the pathogen in the vaccine preparation can result in intact and infectious particles which may cause active infection. Properly produced vaccine is safe and booster shots are required periodically to reinforce the immune response.

Attenuated vaccine- In an attenuated vaccine, live virus or bacteria with very low virulence is used for preparation, which replicate, but locally or very slowly. They do reproduce and continue to present antigen to the immune system beyond the initial type of vaccination and hence boosters may be required less often ${ }^{[18]}$. The attenuation of the pathogen is performed by pass aging, for example, adapting a virus into different host cell cultures, such as in animals, or at suboptimal temperatures, allowing selection of less virulent strains or by mutagenesis or targeted deletions in genes required for virulence and there remains small risk of reversion to virulence ${ }^{[19]}$. Attenuated vaccines cannot be used by immune-compromised individuals ${ }^{[21]}$. Virus-like particle vaccines consist of viral protein(s) derived from the structural proteins of a virus can self-assemble into particles that resemble the virus from which they were derived but lack viral nucleic acid and are not infectious ${ }^{[21]}$. The human papillomavirus ${ }^{[14]}$ and Hepatitis $B^{[22]}$ 
virus vaccines are two virus-like particle-based vaccines currently in clinical use ${ }^{[14]}$.

Subunit vaccine- A subunit vaccine presents an antigen to the immune system without introducing viral particles, whole or otherwise through isolation of a specific protein from a virus or bacterium (such as a bacterial toxin) ${ }^{[18]}$. The isolated proteins may have a different three-dimensional structure than the protein in its normal context, and will induce antibodies that may not recognize the infectious organism ${ }^{[18]}$. This weakness is the biggest drawback of this vaccine; in addition, subunit vaccines often elicit weaker antibody responses than the other classes of vaccines ${ }^{[19]}$.

Toxoid Vaccine- In few instances diseases are caused by the toxins produced by the bacteria as in case of tetanus. The bacterium clostridium tetani produces the toxin that is some neurotoxin named tetanospasmin. In such bacteria immunization is made by inactivating the toxins produced by it via chemicals or by heat treatment ${ }^{[19]}$.

Besides all above described types of vaccination, a number of other vaccine strategies are under experimental investigation and these include DNA vaccination and recombinant viral vectors ${ }^{[23]}$. Vaccines typically contain one or more adjuvants used to boost the immune response. Tetanus toxoid, for instance, is usually adsorbed onto alum and this presents the antigen in such a way as to produce a greater action than the simple aqueous tetanus toxoid ${ }^{[24]}$. People who get an excessive reaction to adsorbed tetanus toxoid may be given the simple vaccine instead of booster doses.

There are various route to vaccine administration; $A$ vaccine may be administered oral, by injection (intramuscular, intradermal \& subcutaneous) by puncture, transdermal or intranasal. Several recent clinical trials are going on, with the aim to deliver the vaccines via mucosal surfaces to be up-taken by the common mucosal immunity system, thus avoiding the need for injections ${ }^{[18]}$. The vaccination averts 2-3 million deaths per year (in all age groups), and up to 1.5 million children die each year due to diseases which could have been prevented by vaccination. These data have been produced by $\mathrm{WHO}^{[25]}$ and according to their estimations, $29 \%$ of deaths of children under five years are vaccine preventable. Ensuring the continued success of vaccination program is the moral responsibility of all the citizens including healthcare professionals, government and industry. Vaccines have very broad impact on the health and there is need of time for appropriate surveillance to evaluate immunization programmes for future success in the field of human health and disease.

\section{CONCLUSIONS}

Vaccines, the biological tools to fight infection in humans, have successfully eradicated the smallpox and polio in many countries. Also there has been substantial decrease in mortality and morbidity rate of infants and children all through the world. Despite many public health successes achieved through vaccination, still a lot of challenges persist in its way to success. In many poor countries where proper infrastructural facilities are not available, the diseases are flourishing at their own pace. Moreover many diseases like malaria, HIV, and Leishmaniasis are spreading drastically due to lack of vaccines, despite vigorous researches conducted in the direction. Also availability of vaccines is minimal in poor countries due to high cost. In few cases effectiveness of vaccines is questionable. Therefore continuous efforts are needed to be done in a direction to develop more effective and low cost vaccines, affordable to every section of the society in this world.

\section{ACKNOWLEDGMENTS}

All the authors duly acknowledge the support of management of Santosh Medical College and Hospital, Ghaziabad, India for writing the manuscript.

\section{CONTRIBUTION OF AUTHORS}

Review concept- Dr. Pradeep Kumar

Review design- Dr. Preeti Sharma

Supervision- Dr. Pradeep Kumar

Materials- Dr. Preeti Sharma \& Dr. Pradeep Kumar

Literature search- Dr. Pradeep

Writing article- Dr. Pradeep

Critical review- Dr. Preeti

Article editing- Dr. Preeti Sharma

Final approval- Dr. Pradeep Kumar

\section{REFERENCES}

[1] Riedel S. Edward Jenner and the history of smallpox and vaccination. Proc. (Bayl Univ Med Cent), 2005; 18(1): 21-25.

[2] Lakhani S. Early clinical pathologists: Edward Jenner (1749-1823). J. Clin. Pathol., 1992; 45: 756-58.

[3] Parish HJ. Victory with Vaccines: The Story of Immunization. Edinburgh: E \& S Livingstone; 1968. 
[4] Stark RB. Immunization saves Washington's army. Surg. Gynecol. Obstet., 1977; 144: 425-31.

[5] Rajan TV. The Gell-Coombs classification of hypersensitivity reactions: A re-interpretation. Trends Immunol., 2003; 24 (7): 376-9.

[6] Kumar V, Abbas A, Fausto N, Aster J. Robbins and Cotran Pathologic Basis of Disease, Professional Edition, $8^{\text {th }}$ edition. Elsevier; 2010, 1464.

[7] Willis NJ. Edward Jenner and the eradication of smallpox. Scott. Med. J., 1997; 42: 118-21.

[8] Holmes CB, Losina E, Walensky RP, Yazdanpanah Y, Freedberg KA. Review of human immunodeficiency virus type 1-related opportunistic infections in subSaharan Africa. Clin. Infect. Dis., 2003; 36(5): 652-62.

[9] Sepkowitz KA. AIDS- The first 20 years. N. Engl. J. Med., 2001; 344(23): 1764-72.

[10] Manara AR, Murphy PG, O'Callaghan G. Donation after circulatory death. British J. Anaesth., 2011, 108: 108-21.

[11] Grinyo JM. Why is Organ Transplantation Clinically Important? Cold Spring Harb. Perspect. Med., 2013; 3(6): a014985.

[12]Lombard M, Pastoret PP, Moulin A. A brief history of vaccines and vaccination. Revue Scientifique Et. Technique, 2007; 26(1): 29-48.

[13] Manzoli L, loannidis JP, Flacco ME, De Vito C, Villari P. Effectiveness and harms of seasonal and pandemic influenza vaccines in children, adults and elderly: a critical review and re-analysis of 15 metaanalyses. Hum. Vaccin. Immunother., 2012; 8(7): 851-62.

[14]Kash N, Lee MA, Kollipara R, Downing C, Guidry J, Tyring SK. Safety and Efficacy Data on Vaccines and Immunization to Human Papillomavirus. J. Clin. Med., 2015; 4(4): 614-33.

[15]Carrillo-Santisteve P, Lopalco PL. Varicella vaccination: A laboured take-off. Clin. Microbiol. Infect., 2014; 20(S5): 86-91.
[16]Greenwood B. The contribution of vaccination to global health: past, present and future. Philos. Trans. R. Soc. Lond. B. Biol. Sci., 2014; 369(1645): 20130433.

[17]Barquet N, Domingo P. Smallpox: the triumph over the most terrible of the ministers of death. Ann. Intern. Med., 1997; 127(8 Pt1): 635-42.

[18]Petrovsky N, Aguilar JC. Vaccine adjuvants: Current state and future trends. Immunol. Cell Biol., 2004; 82(5): 488-96.

[19]Fiore $A E$, Bridges $C B$, Cox NJ. Seasonal influenza vaccines. Curr. Top. Microbiol. Immunol., 2009; 333: 43-82.

[20]Keelan J, Wilson K. Balancing Vaccine Science and National Policy Objectives: Lessons from the National Vaccine Injury Compensation Program Omnibus Autism Proceedings. Am. J. Public Health, 2011; 101(11): 2016-21.

[21]L'Huillier AG, Posfay-Barbe KM. Live Viral Vaccines in immunocompromised Patients. Future Virol., 2014; 9(2): 161-71.

[22] WHO. Hepatitis B vaccines WHO position paper. Weekly epidemiological record (WER), 2009; 84(40): 405-20.

[23]Nascimento IP, Leite LCC. Recombinant vaccines and the development of new vaccine strategies. Braz. J. Med. Biol. Res., 2012; 45(12): 1102-11.

[24]CDC. National Childhood Vaccine Injury Act: requirements for permanent vaccination records and for reporting of selected events after vaccination. MMWR, 1988; 37: 197-200.

[25]Magazine- Immunization facts and figures Nov 2015 update world immunization week, 2015. https://www.who.int/news-room/fact-sheets/detail/ immunization-coverage. 